\title{
Determinants Factors for the Choice of the Width Prosthetic Upper Central Incisor: Review of the Literature
}

\author{
Kumpanya Ntumba Pierrot ${ }^{1}$, Sekele Isouradi Bourley Jean Paul 1*, Kasiama1, \\ Mudogo Nzanzu Celestin², Mantshumba Milolo Augustin ${ }^{1}$, Lutula Pene Shenda Joseph 2, \\ Bolenge $^{3}$, Nyimi Bushabu Fidele ${ }^{2}$
}

${ }^{1}$ Department of Dental Medicine, Prosthodontics and Orthodontics Service, Faculty of Medicine, University of Kinshasa, Kinshasa, Democratic Republic of Congo

${ }^{2}$ Department of Dental Medicine, Oral and Maxillofacial Surgery Service, Faculty of Medicine, Kinshasa University, Kinshasa, Democratic Republic of Congo

${ }^{3}$ Department of Dental Medicine, Periodontology Unit, Faculty of Medicine, Kinshasa University, Kinshasa, Democratic Republic of Congo

Email: *jp.sekele@unikin.ac.cd

How to cite this paper: Pierrot, K.N., Paul, S.I.B.J., Kasiama, Celestin, M.N., Augustin, M.M., Joseph, L.P.S., Bolenge and Fidele, N.B. (2020) Determinants Factors for the Choice of the Width Prosthetic Upper Central Incisor: Review of the Literature. Open Journal of Stomatology, 10, 333-340. https://doi.org/10.4236/ojst.2020.1011031

Received: September 17, 2020 Accepted: November 16, 2020 Published: November 19, 2020

Copyright $\odot 2020$ by author(s) and Scientific Research Publishing Inc. This work is licensed under the Creative Commons Attribution International License (CC BY 4.0).

http://creativecommons.org/licenses/by/4.0/ (c) (i) Open Access

\begin{abstract}
Materials and Methods: The authors conducted a review of the literature around the theme, determinants of the choice of the width of the upper central incisor (WUCI), through search web including Pub Med, Inari and Google. Fifteen of the most recent publications since 2005 have been selected from twenty publications. Sample size (n), age range (AR), average bi zygomatic distance (BZD), choice determinants, type of study, and mathematical formula between WUCI and BZD were the study's interest variables. Sociodemographic characteristics, facial anatomical marks and the size of the patient's teeth for anterosuperior were the main factors to be assessed. Results: Out of 22 included articles, the Asian continent represents 59\% in which India is the leading country with $27.3 \%$ followed by American $22.8 \%$. The most Determinants choice for the width upper central incisor in craniofacial and anterior teeth method from the published papers were BZD $(100 \% ; n=22)$ and WUCI $(81.8 \% ; \mathrm{n}=18)$. Conclusion: Application of mathematical formulation maybe help to predict the exact width of the upper central incisor.
\end{abstract}

\section{Keywords}

Choice Determinants, Width, Upper Central Incisor, Prosthetic, Completed Edentulous 


\section{Introduction}

The success or failure of prosthetic treatment depends in great part on the step of choosing the upper anterior teeth dimension [1]. The latter requires careful reflection and the arithmetic calculations of the practitioner [2]. On the other hand, it might need during the consultation; a series of anatomical constitutive unit or sociodemographic of the patient such as the shape of the face and nose, the color of the patient's eyes, hair and skin, sex, personality and age [3]; as well as the ethnicity, race, region, continents, weight, etc. All of these factors maybe make the choice of the width of the top six anterior teeth (W6AT) or the upper central incisor (UCI) not only difficult [4], but also very complex. In addition, the genetic, hormonal, environmental, climatic, social and food factors of each individual as well as the customs of the population; may influence the craniofacial and dental dimension, especially in children population [5] [6]. In 1996, Hillson demonstrated in England that dietary factors could affect musculature and swallowing [7]. Antero-superior teeth are the key elements that contribute to the importance of aesthetic and beauty of dental facial [8]. It remain overrun the second position after the eyes in the appearance of the face [9]. The Upper Central Incisor (UCI) is considered as the star of all teeth; the most desired, cited and the most studied in relation to other teeth [10]. It is the most aesthetically pleasing tooth in the previous sector for its visibility in the mouth [11] [12].

In the case of complete edentulous in adulthood, especially in the absence of pre-extraction documents, the practitioner is called upon to make a judicious choice of one or whatever facial mark, and a series of aforementioned factors maybe help to determine either the width of an upper central incisor or the group of anterior teeth. To the best of our knowledge, no studies have been conducted in the Democratic Republic of Congo (RD Congo) about the determinants factors of choice of the width prosthetic upper central incisor. The aim of the study was to make an inventory of published articles about the determinants factors of choice for prosthetic WUCI in order to foresee the mathematical formulation between the WUCI and the BZD among the Congolese.

\section{Materials and Methods}

A review of the literature was performed in June 2020 using MEDLINE, PubMed, Scopus, Inari and Google. Keywords included the following terms: determinants, choice, width, upper central incisive, complete tooth. We selected the most recent articles of interest from 2005 to 2019. Reference lists of all articles retrieved from databases search were also selected for further relevant studies. Abstracts were reviewed and relevant articles were given more attention, and if possible, reviewed in full. Prospective or retrospective clinical studies, with a sample size of $\mathrm{n} \geq$ five, in which the main focus was on data regarding age range, BZD average, WUCI selection determinants factors, and mathematical formula used between WUCI and BZD were evaluated and included in this review. Exclusion criteria were studies with unclear reporting of the aforementioned variables, nonhuman studies, letters, preface and comments. After the full 
reading out of 25 articles, only $22(88 \%)$ articles were included in the quantitative synthesis for the review.

\section{Results}

Out of 22 included articles, the Asian continent represents 59\% in which India is the leading country with $27.3 \%$ followed by American $22.8 \%$ (Table 1 ). The most Determinants choice for the width upper central incisor in craniofacial method from the published papers were BZD $(100 \% ; n=22)$ followed by ICOD $(30 \% ; n=7)$ and WUCI $(81.8 \% ; n=18)$ followed by ICCD $(18.2 \% ; n=4)$ for anterior teeth method (Table 2). The average BZD is variable according to gender, race and ethnicity (Table 3 ).

\section{Comments}

The present research indicated that the most selected articles are in the Asian continent. Many authors have developed the choice techniques based on the proportions in Caucasian subjects [1] as well as for American publications. In Africa, however, there are insufficient studies maybe because of the different morphogenetic and typological observed in the maxillofacial area.

Determinant factors of the choice of the width of the upper central incisor (WUCI) are divided into three groups including socio-demographic factors, craniofacial and dental determinants factors. Age and gender are the most basic represented socio-demographic determinants in the literature. The sex is a factor that affect the width of the upper central incisor significantly and designates the smile [13]. However, typology is a support factor for age and sex. They affect the aesthetics and designates the smile [13]. However, typology is a support factor for age and sex that helps to create a pleasant-looking tooth [14]. Additionally, ethnicity and race are considered a complementary factor to gender, personality and age. An individual's age, gender, typology, race, weight and body size could be called controllable socio-demographic determinants. Practitioners can easily classify and manage these factors. A statistical relationship between these factors and tooth width may be established. In addition, heredity, tribe, hormones, environment, ethnicity (R.D.C), etc. are uncontrollable determinants. They require a lot of administrative procedures, additional reviews, and proof of finances and

Table 1. Breakdown of selected items by continent.

\begin{tabular}{cc}
\hline Continents & Effective (Percentage) \\
\hline Asian & $13(59 \%)$ \\
American & $5(22.8 \%)$ \\
African & $3(13.7 \%)$ \\
European & $1(4.5 \%)$ \\
Total & $22(100 \%)$ \\
\hline
\end{tabular}


N. O. Kumpanya et al.

Table 2. Determinants choice of the WUCI.

\begin{tabular}{|c|c|c|c|c|}
\hline Author & Year & Socio-demographic & Cranio-facial & Anterior teeth \\
\hline Hasanreisoglu et al. & 2005 & Sex, age & ICOD, BZD, ID & WUCI, WULI, LULI, ICCD \\
\hline Fabiana & 2005 & Sex, age, race & BZD & WUCI, WULI, LULI,W6AT \\
\hline Nagham & 2005 & Sex, age, typology & $\begin{array}{l}\text { BZD, DICE, ICD, IWD, ID, } \\
\text { ICOD, IPD }\end{array}$ & WUCI, ICCD \\
\hline Bamba et al. & 2006 & Sex, age & BZD, ID & WUCI, ICCD \\
\hline Umar et al. & 2006 & Sex, age, typology, weight & BZD, ID, Skull, Tete & \\
\hline Oliveira's Strong & 2012 & Sex, age & $\begin{array}{l}\mathrm{BZD}, \mathrm{Na}, \mathrm{Eu}, \mathrm{Ba}, \mathrm{Br} \text {, Glabelle } \\
\text { Lambda, Inion, Mastoid }\end{array}$ & \\
\hline Schuchita et al. & 2012 & Sex, age & ID, BZD, ICD, IWD & WUCI, ICCD \\
\hline Bhashar et al. & 2013 & Sex, age & BZD & WUCI, \\
\hline Jafari et al. & 2014 & Sex, age & BZD, ICOD & WUCI \\
\hline Gueye et al. & 2014 & Sex, age & BZD & WUCI, UICD \\
\hline Ankita & 2015 & Sex, age & BZD & WUCI \\
\hline Sameen et al. & 2015 & Sex, age & BZD, ICOD, IPD, ID & WUCI, W2UCI, ICCD \\
\hline Khin et al. & 2015 & Sex, age, ethnicity & BZD & \\
\hline Palathottungal et al. & 2015 & Sex, age & BZD & WUCI \\
\hline Mohammed et al. & 2017 & Sex, age & $\begin{array}{l}\text { BZD, ID, ICOD, DIC, ITD, } \\
\text { FP, UIP }\end{array}$ & WUCI, LUCI, W6AT \\
\hline Waseem et al. & 2017 & Sex, age & BZD, ID, ICOD & WUCI, LUCI, W6AT \\
\hline Ewa et al. & 2017 & Sex, age, ethnicity & BZD, IWD, ICD, & WUCI, W2UCI, W4UI \\
\hline Shakir et al. & 2017 & Sex, age & BZD & WUCI \\
\hline Bhagat et al. & 2018 & Sex, age & BZD & WUCI \\
\hline Aead et al. & 2019 & Sex, age & DBZ, ID, ICCD, IWD & WUCI \\
\hline Abitha et al. & 2019 & Sex, age & BZD & WUCI \\
\hline Debnath et al. & 2019 & Sex, age & BZD & \\
\hline
\end{tabular}

Legend: BZD: Bizygomatic distance; ID: Intercalar distance; ICD: Intercanthal distance; ICCD: Inter-commissure distance; ICOD: Intercondylar distance; UICD: Upper intercuspidian distance; IPD: Interphiltrum distance; IWD: inter ward distance; ITD: Inter tuberosity distance; FP: Fovea palatine; WUC: Width upper canine; W6AT: Width of the six anterior teeth; W2UCI: width of the two upper central incisors; W4UI: Width of the four upper incisors; WUCI: Width of the upper central incisor; WULI: Width of the upper lateral incisor; LUCI: Length of upper central incisor; LULI: Length of upper lateral incisor; LUC: Length of upper canine; UIP: upper incisive papilla; NA: Nasion; EU: Euryon; BA: Basion; BR: Bregma.

time. Thus mean that it is very difficult, if not impossible, to use them as determinants factors, in order to determine the width of an upper central incisor (UCI). One might be tempted to apply the controllable socio-demographic dependent or independent variables in order to reach one or more mathematical formulas.

These determinants can be used in young adults (18 years) of age; because its growth has ended; and that the inter-dental contact points of incisive are still visible to the naked eye. The same is true for older people, although there is attrition or dental wear in the mouth [15] [16].

However, it should reserve for a child in times of growth. The skin and bone points of the face and the interdental points are unstable. This would not 
Table 3. BZD average and WUCI formula.

\begin{tabular}{|c|c|c|c|}
\hline Authors and countries & Year & BZD Average & Formula used \\
\hline Fabiana et al. (Brazil) & 2005 & $\begin{array}{l}\text { BZD }(\text { White })=135.48 \pm 7.73 \mathrm{~mm} \\
\text { BZD }(\text { Black })=138.47 \pm 8.31 \mathrm{~mm} \\
\text { BZD }(\text { Métis })=134.58 \pm 6.84 \mathrm{~mm} \\
\text { BZD }(\text { Asian })=140.04 \pm 6.59 \mathrm{~mm}\end{array}$ & \\
\hline Nagham et al. (Iraq) & 2005 & $\begin{array}{l}\mathrm{BZD}(\mathrm{M})=118.96 \pm 7.4 \mathrm{~mm} \\
\mathrm{BZD}(\mathrm{F})=108.92 \pm 7.92 \mathrm{~mm}\end{array}$ & $\mathrm{WUCI}=\frac{\mathrm{BZD}}{12.34}$ or $\mathrm{WUCI}=\mathrm{BZD} \times 0.08$ \\
\hline Hasanreisoglu et al. (Turkey) & 2005 & & $\mathrm{WUCI}(\mathrm{F})=\frac{\mathrm{BZD}}{16}$ \\
\hline Bamba et al. (ivory rating) & 2006 & $\mathrm{BZD}=129.182 \pm 6.82 \mathrm{~mm}$ & $\mathrm{WUCI}=\frac{\mathrm{BZD}}{14.6}$ \\
\hline Umar et al. (Nigeria) & 2006 & $\mathrm{BZD}=122.496 \pm 1.165 \mathrm{~mm}$ & \\
\hline Fortes d'Oliveira (Brazil) & 2012 & $\begin{array}{l}\text { BZD }(M)=110.88 \pm 7.06 \mathrm{~mm} \\
B Z D(F)=103.29 \pm 5.99 \mathrm{~mm}\end{array}$ & \\
\hline Schuchita et al. & 2012 & $\begin{array}{l}\mathrm{BZD}(\mathrm{M})=114.36 \pm 6.95 \mathrm{~mm} \\
\mathrm{BZD}(\mathrm{F})=110.42 \pm 4.44 \mathrm{~mm} \\
\mathrm{BZD}=112 \mathrm{~mm}\end{array}$ & $\begin{array}{l}\operatorname{WUCI}(\mathrm{M})=\frac{\text { BZD }}{14} \\
\operatorname{WUCI}(\mathrm{F})=\frac{\text { BZD }}{13.7}\end{array}$ \\
\hline Gueye et al. (Sénégal) & 2014 & $\mathrm{BZD}=137.8 \pm 5.72 \mathrm{~mm}$ & $\mathrm{WUCI}=\frac{\mathrm{BZD}}{15.13}$ \\
\hline Jafari et al. (Iran) & 2014 & $\mathrm{BZD}=129.2 \pm 7.36 \mathrm{~mm}$ & \\
\hline Ankita et al. (India) & 2015 & $\begin{array}{l}\mathrm{BZD}(\mathrm{M})=119.76 \pm 0.47 \mathrm{~mm} \\
\mathrm{BZD}(\mathrm{F})=118.43 \pm 0.46 \mathrm{~mm}\end{array}$ & \\
\hline Sameen et al. (Pakistan) & 2015 & $\mathrm{BZD}=103.31 \pm 7.62 \mathrm{~mm}$ & WUCI $=\frac{\text { BZD }}{12}$ \\
\hline Bedoya et al. (Colombia) & 2015 & $\begin{array}{l}\mathrm{BZD}(\text { metis })=113.3 \pm 6.4 \mathrm{~mm} \\
\mathrm{BZD}(\text { Afro-Colombian })=108.9 \pm 8.8 \mathrm{~mm} \\
\mathrm{BZD}(\text { ticuna })=132.4 \pm 4.5 \mathrm{~mm}\end{array}$ & \\
\hline Khin et al. (Malaysia) & 2015 & $\begin{array}{l}\text { BZD }(\text { Malaysian })=135.16 \pm 6.48 \mathrm{~mm} \\
\text { BZD }(M)=111.2 \pm 10.32 \mathrm{~mm} \\
B Z D(F)=131.5 \pm 8.8 \mathrm{~mm} \\
B Z D(\text { Chinese })=131.72 \pm 8.96 \mathrm{~mm} \\
\text { BZD (Malaysian) }=135.16 \pm 6.48 \mathrm{~mm} \\
B Z D(\text { Chinese })=131.72 \pm 8.96 \mathrm{~mm} \\
B D Z(M)=136.15 \pm 7.33 \mathrm{~mm} \\
B Z D(F)=131.18 \pm 7.83 \mathrm{~mm}\end{array}$ & \\
\hline Palathttungal et al. (India) & 2015 & $\begin{array}{l}\operatorname{BZD}(\mathrm{M})=125.4 \mathrm{~mm} \\
\operatorname{BZD}(\mathrm{F})=124.2 \mathrm{~mm}\end{array}$ & $\mathrm{DICS}=\frac{\mathrm{BZD}}{16}$ \\
\hline Mohammed et al. (Saudi Arabia) & 2017 & $\mathrm{BZD}=120.2 \pm 13.96 \mathrm{~mm}$ & $\mathrm{WUCI}=\frac{\mathrm{BZD}}{16}$ \\
\hline Shakir et al. (Pakistan) & 2017 & $\begin{array}{l}\mathrm{BZD}(\mathrm{M})=112.04 \mathrm{~mm} \\
\mathrm{BZD}(\mathrm{F})=109.45 \mathrm{~mm} \\
\mathrm{BZD}=111.307 \pm 2.870 \mathrm{~mm}\end{array}$ & $\mathrm{WUCI}=\frac{\mathrm{BZD}}{13}$ \\
\hline
\end{tabular}




\section{Continued}

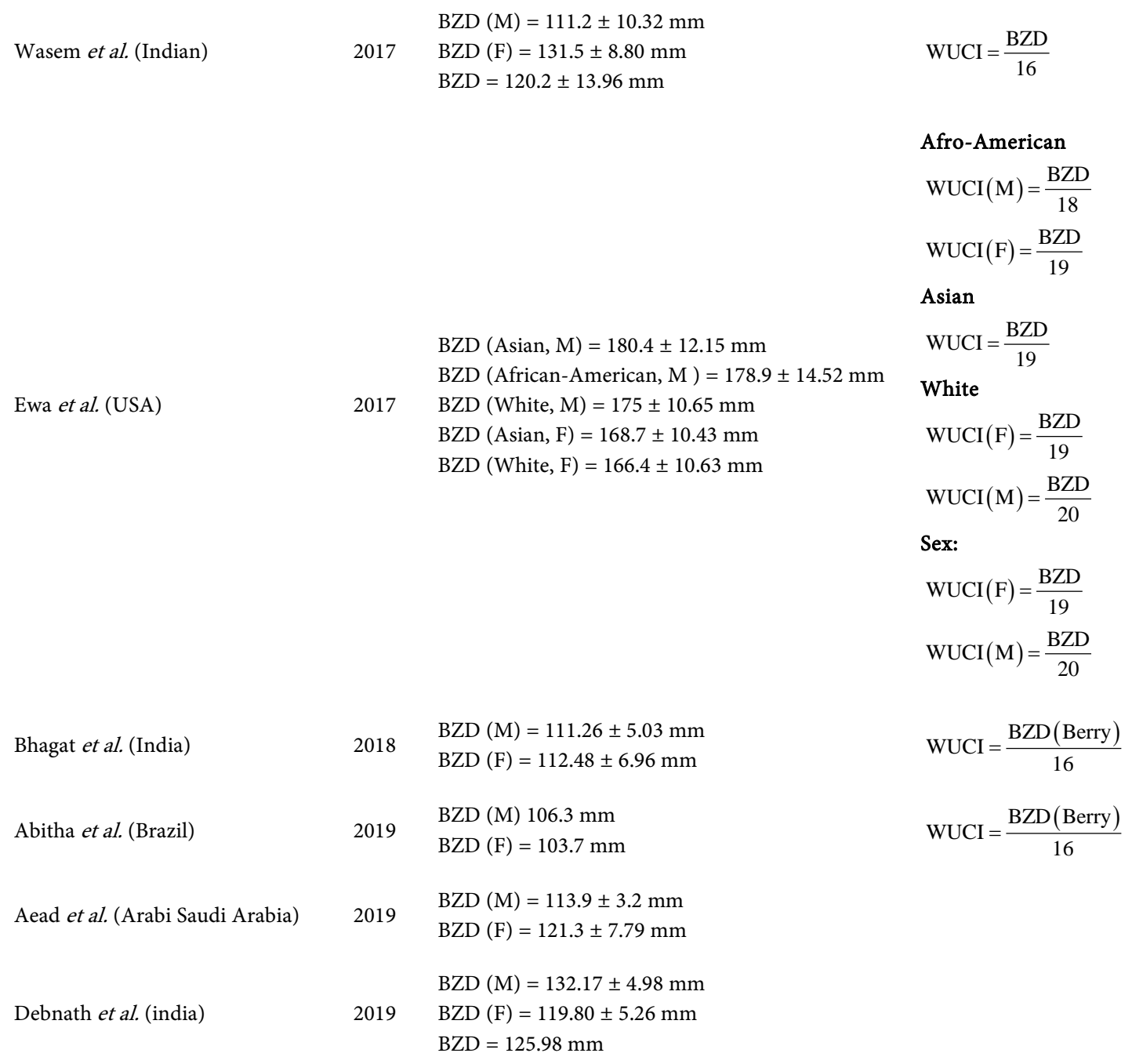

Legend. BZD: bizygomatic distance; WUCI: Width of the upper central incisor; M: male and F: female.

facilitate the measurement of the UCI point of contact. BZD, IWD, ID, ICD, and ICOD are used as first-line frontal parameters; where a total toothless patient has no pre-extraction documents in the dental hospital environment [17] [18] [19] [20]. However, many authors advocate the combination of these facial parameters in determining the choice of width of the anterior teeth [19] [20] [21]. The average BZD is variable according to gender [22] [23] [8], race [24] and ethnicity [25] [26]. The bizygomatic width among Europeans appears to be smaller compared to that of Africans and Asians. The formula between BZD and WUCI is always obtained in proportion form. This ratio is equal to ${ }_{1 / 16}$ in several Asian and European countries [11] [27] [28]. However, this proportion is less than $_{1 / 16}$ in Africa [1] [29]; but also more than 1/16 in some countries.

\section{Conclusion}

Demographic, craniofacial and dental determinants of toothed subjects can lead 
to a reliable, applicable mathematical formulation to predict the exact width of the upper central incisor. No standard mathematical formulation between BZD and WUCI has been listed in the literature.

\section{Conflicts of Interest}

The authors declare no conflicts of interest regarding the publication of this paper.

\section{References}

[1] N'dindin, A.C., N'guessan, K.S., Assi, K.D., Bitty, M.J. and Ohomon, O.R. (2002) Choice of Size of Anterior Teeth in Black African Patients. Tropical Odontostomatology, 100, 2-12.

[2] Radia bennelaid. (2007) Complete Prosthesis and Choice of Teeth "The Smile Is Found". Cosmetic file of the Dental Surgeon of France, 1316, 28-34.

[3] Brunetto, J., Becker, M. and Volpatoca, M. (2011) Gender Differences in the Form Software. Journal of Prosthetic Dentistry, 106, 95-101. https://doi.org/10.1016/S0022-3913(11)60102-9

[4] Neda, A.K. and Balkees, T.G. (2016) Selecting Maxillary Anterior Teeth Width by Measuring Certain Facial Dimensions in the Kurdish Population. Journal of Prosthetic Dentistry, 115, 321-329. https://doi.org/10.1016/j.prosdent.2015.08.012

[5] Fearne, J, Brook, A.H. (1993) Small Primary Tooth Crown Size in Low Birth Weight Children. Early Human Development, 33, 81-90. https://doi.org/10.1016/0378-3782(93)90203-7

[6] Tousend, G. and Alversalo, L. (1985) Tooth Size in 47, XYY Males. Evidence for a Direct Effect of the Y Chromosome on Growth. Australian Dental Journal Australian Dental Journal, 30, 268-272. https://doi.org/10.1111/j.1834-7819.1985.tb02507.x

[7] Hillson, S., Archana, N. and Verma, P.R. (2012) Correlation between Facial Measurements and the Mesiodistal Width of the Maxillary Anterior Teeth. India Journal of Dental Sciences, 4, 20-24.

[8] Shuchita, S., Archana, N. and Verma, P.R. (2012) Correlation between Facial Measurements and the Mesiodistal Width of the Maxillary Anterior Teeth. India Journal of Dental Sciences, 4, 20-24.

[9] Mariani, P. (1992) Choice of Artificial Tooth Color in Complete Toothlessness; Conclusion of a Color Study of Natural Teeth A.O.S.

[10] Paris, J.C. and Etienne, J.M. (2007) At the Center of the Smile of the Central Incisor. International Dental Journal, 89, 1007-1012.

[11] Hasanreisoglu, U., Berksun, S. and Arslam, I. (2005) An Analysis of Maxillary Anterior Teeth: Facial and Dental Proportions. Journal of Prosthetic Dentistry, 94, 530-538. https://doi.org/10.1016/j.prosdent.2005.10.007

[12] Akeel, R. (2003) Attitude of Sandi Male Patients towards the Appearance of Natural Anterior Teeth. Journal of Prosthetic Dentistry, 90, 571-577. https://doi.org/10.1016/j.prosdent.2003.09.007

[13] Nahed khali,l A. (2019) Factors Affecting Esthetics and Design of the Smile. Current Science International, 8, 810-819.

[14] Cheylan, J.M. (2016) Personalization of the Aesthetic Assembly into a Complete Prosthesis. Prosthetic Strategy, 16, 257-266. 
[15] Bandevik, O. (1998) Changes in Occlusion between 23 and 34 Years of Age. The Angle Orthodontist, 68, 75-80.

[16] Khangura, R.K., Sircar, K. and Singh, S. and Rastogi, V. (2011) Sex Determination Using Mesiodistal Dimension of Permanent Maxillary Incisions and Canines. Journal of Forensic Dental Sciences, 3, 81-85. https://doi.org/10.4103/0975-1475.92152

[17] Sinavarat, P. (2013) The Relationship of Maxillary Canines to the Facial Anatomical Land Marks in a Group of the Thai People. The Journal of Advanced Prosthodontics, 5, 369-373. https://doi.org/10.4047/jap.2013.5.4.369

[18] Kini, A.Y. and Angadi, G.S. (2013) Biometry Ratio in Estimating Width of Maxillary Measurements with Dental Measurements. Gerondontology, 30, 106-111.

[19] Isa, Z.M., Tawfiq, O.F., et al. (2010) Regression Methods to Investigate the Relationship between Facial Measurements and Widths of the Maxillary Anterior Teeth. The Journal of Prosthetic Dentistry, 103, 182-188. https://doi.org/10.1016/S0022-3913(10)60028-5

[20] Varjao, F.M. and Nogueira, S.S. (2005) Intercommissural Width in 4 Racial Groups as a Guide for the Selection of Maxillary Anterior Teeth in Complete Denture. The International Journal of Prosthodontics, 18, 513-515.

[21] Latta, G.H., Weaver, J.R. and Conkin, J.E. (1991) The Relationship between Width of Mouth, Interalar Width, Bizygomatic Width, and Interpupillary Distance in Edentulous Patients. Journal of Prosthetic Dentistry, 65, 250-265. https://doi.org/10.1016/0022-3913(91)90170-2

[22] Abitha, T. and Santhanam, A. (2019) Correlation between Bizygomatic and Maxillary Central Incisor Width for Gender Identification. Brazilian Dental Science, 22, 458-466. https://doi.org/10.14295/bds.2019.v22i4.1775

[23] Shakir, A.H., Hussein, H.S., Qadir, M.A. and Kazanji, M. (2017) Relation of Maxillary Central Incisor Width to Some Facial Measurements. The Journal of Oral and Dental Research, 4, 93-101. https://doi.org/10.12816/0038704

[24] Fabiana, M.V., et al. (2005) Area de concentrçao in prosthesisuniv Estadual Paulista Julio de mesquita. Araquara Bresilia, 133.

[25] Bedoya, A., Osorio, J.C. and Tamaya, J.A. (2015) Dental Arch Size, Biting Force, Bizygomatic Width and Face Height in Three Colombian Ethnic Groups. International Journal of Morphology, 3, 55-61. https://doi.org/10.4067/S0717-95022015000100009

[26] Khin, M.T., Than, W., Jayasingwe, J.A.P. and Nizam, A. (2015) The Maxillary Arch and Cephalometrie Measurements: Comparing Ethnic Malay and Ethnic Chinese in Malaysia. International Journal of Anatomy and Research, 3, 999-1007.

https://doi.org/10.16965/ijar.2015.140

[27] Palathottungal, J.A, Karthigaka, S.P., Giju, B.G., Thomas, V. and Mohammed, S.P. (2015) Applicability of Berry's Index in Bite Mark Analysis. Journal of Forensic Dental Science, 7, 28-31. https://doi.org/10.4103/0975-1475.150299

[28] Condon, M., Bready, M., Quinn, F., O’Connell, B.C., Houston, F.J. and O'Sullivian, M. (2011) Maxillary Anterior Tooth Dimensions and Proportions in an Irish Young Adult Population. Journal of Oral Rehabilitation, 38, 501-508. https://doi.org/10.1111/j.1365-2842.2010.02181.x

[29] Bamba, A., Kouakou, N.C., Amicha, K.J.C., et al. (2006) Règles bio morphologiques de rétablissement prothétique de l'esthétique maxillo-faciale: Fiabilité chez le sujet Mélano-Africain. Rev col odonstomatol. Africa Chirurgie Maxillo-Faciale, 13, 33-38. 